\title{
Civil Engineering

\section{Polypropylene Microfibers Against Explosive Spalling of Concrete. Strength Properties of Concrete with Fiber}

\author{
Sergey Antonov* \\ Fire protection of building constructions, Russia
}

Submission: October 17, 2018; Published: November 13, 2018

*Corresponding author: Sergey Antonov, Fire protection of building constructions, Russia

\section{Mini Review}

Russian fire-safety legislation, applied to fire resistance of building constructions by loss of bearing capacity (R), seems unfinished contradictory (to other legislations) to many specialists. Nevertheless, ministry of construction in Russia considers that applied to fire resistance it is harmonized enough, the objects are specified and instruments of law enforcement exist (such as 384-FZ, 123-FZ, sets of rules and GOSTs - state standards). Firstly, Russian legislation makes no distinction between load-bearing and self-supporting constructions, whether they are under or over ground, made from concrete, wood or steel etc. Each one of them while being designed or exploited must have a proven fire resistance. It is mentioned in 384- $\$ 3$ «Technical safety regulation for buildings and constructions» in clause 5 : «1. Buildings and constructions' safety, as well as related processes such as design, engineering, installation, adjustment, exploitation, utilization (demolition), is provided through the setting of meeting the safety requirements design values of parameters of buildings and constructions; qualitative characteristics during the whole life cycle of building/construction. Safety depends on implementation of specified values and characteristics during the building process, reconstruction, overhaul (hereinafter «building») and their further maintenance». And even if 384-FZ lacks some technical requirements, then according to this same standard, point 3.5 « Additional buildings' safety requirements can be set by other technical regulations. However, they cannot contradict the requirements of the given federal law». (we will refer to this point later). Thus, while developing project decision, the constructor must be sure that fire resistance of the designed constructions complies with legislation. It's his direct duty. Russian town-planning code № 190-FZ from 29.12.2004 has a mention in clause 48.

\section{Architectural and Construction Design}

«Preparation of project documentation is carried out based on the task of the developer/technical builder (when preparing project documentation on the basis of an agreement), results of engineering surveys, information, specified in urban-planning scheme of section; in case of making a project documentation for a linear object on the basis of the territorial planning project/ land surveying project in accordance with technical regulations, technical conditions, deviation from limit parameters of permitted construction, reconstruction of capital construction projects». It is indicated in clause 87 point 9123 -FZ that «fire resistance limits and fire safety classes of building constructions must be determined under standard conditions». The same clause point 10 allows to determine fire resistance by computationalanalytical method, but exceptionally for «building constructions similar in form, materials, structural design to the constructions which had passed the fire tests».

\section{How do you test these materials?}

There is a whole list of regulations enacted by the directive of Russian government from 11.06.2015 №1092, where it’s said: Proposed changes, which are put on the list of national standards, containing rules and methods of research (tests)/measurements, including sampling rules necessary for the implementation of the federal law «Technical regulations on fire safety requirements» and conformity assessment, enacted by the directive of Russian government from 10.03.2009 №304-p (Russian national legislation, 2011, № 11, p. 1363; 2011, № 5, p. 762) must be approved». Please note that there is no phrase «on a voluntary basis» in this preamble. It is replaced by the words «necessary for application and execution». In chapter «Fire-technical classification of building constructions and fire barriers» of this list we are interested, for example, in these documents:

A. 57. GOST 30247.0-94 (ISO 834-75) «Building constructions. Fire test methods. General requirements» [1];

B. 58. GOST 30247.1-94 «Building constructions. Fire test methods. Load-bearing constructions and walling» [2];

C. 59. GOST 30403-2012 «Building constructions. Methods for determining fire safety»;

D. 60. GOST 31251-2008 «Building constructions. Methods for determining fire safety. Exterior walls on the outside»; 


\section{Civil Engineering Research Journal}

E. 66. GOST P 53309-2009 «Buildings and fragments of buildings. Method of actual fire tests. General requirements»;

F. 105. GOST P 53295-2009 «Fire protection means for steel structures. General requirements. Flame retardant effectiveness test method».

Having carefully studied $123-\Phi 3$ and this list you will see that to implement the law, it is necessary to carry out two types of fire tests

a. For building constructions: All load-bearing and self-supporting constructions must pass fire tests according to GOST 30247.1 «Building constructions. Fire test methods. Load-bearing constructions and walling», namely, considering that is says in point 7.2.1: «Samples of load-bearing and self-supporting constructions must be tested under load»;

b. for fire protection means (in our case - for fire retardant coatings): If fire retardant coatings are used to increase fire resistance, they must get the required certificate while being tested by GOST P 53295-2009. «Fire protection means for steel structures. General requirements. Flame retardant effectiveness test method».

Based on this clause 87, only 2 documents can prove the fire resistance of a structure, building or construction:

I. Fire test report

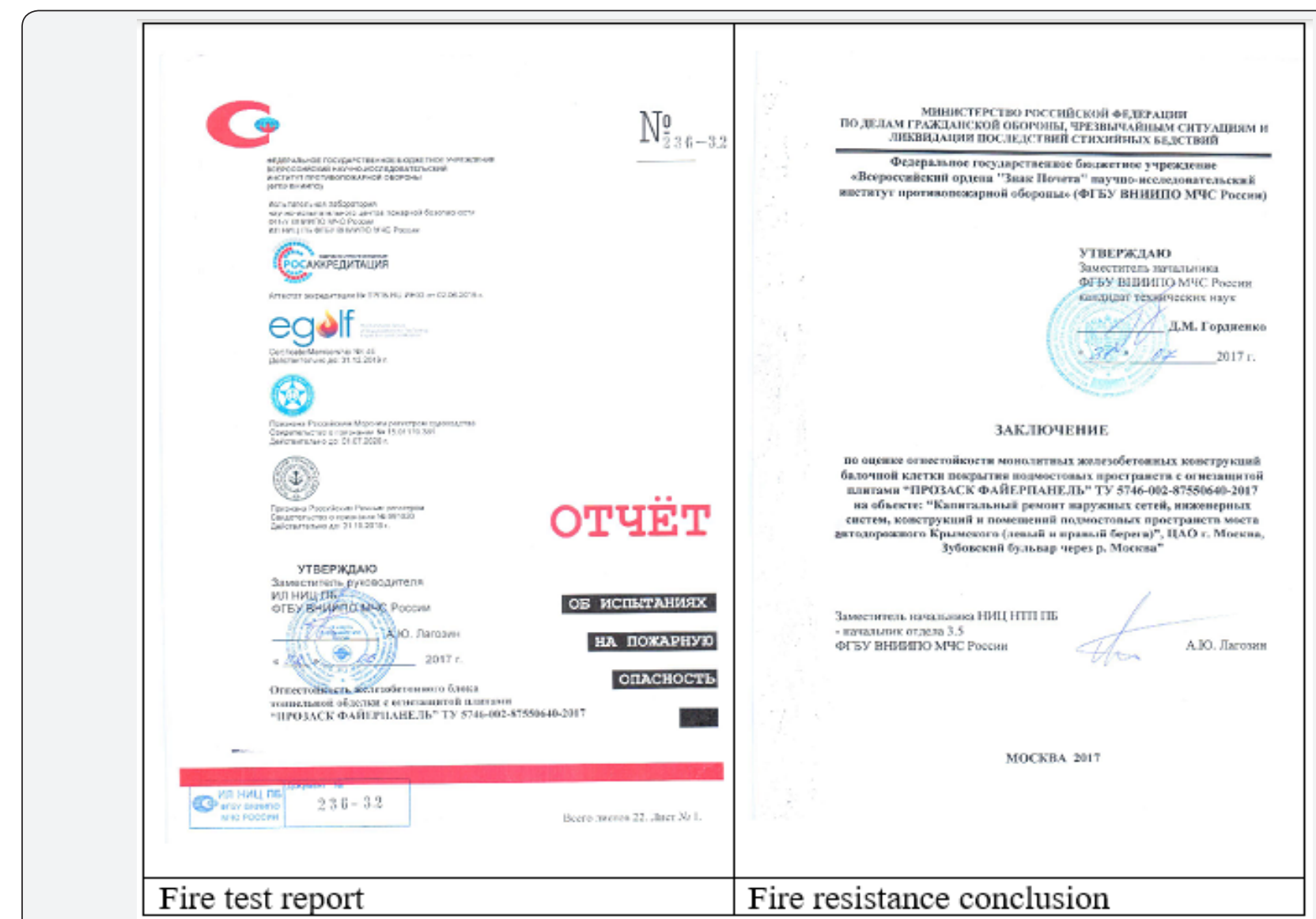

Figure 1: Fire resistance conclusion based on testing of similar structures.

Only in these two cases the letter R appears in the conclusion!

II. Fire resistance conclusion based on testing of similar structures (Figure 1)

What is the meaning of tests under load? Obviously not to figure out which temperature of metal (e.g. $430{ }^{\circ} \mathrm{C}, 500^{\circ} \mathrm{C}$ or 673 ${ }^{\circ} \mathrm{C}$ ) or steel reinforcement in concrete is critical under specific load. All this data is commonly known for a long time. Tests under load are being carried out for the purpose of obtaining experimental data on the effect of stress-strain structural state on the change in fire resistance of the structure. Of course, distracting from the tests we can say that there are some questions concerning the application of calculation methods (which are not officially approved by Russian government!). In 2016 Russian Emergency
Situations Ministry clarified: «Thus, in the case of a similar design of building structures, which have been tested before, as well as design stresses and support conditions, what is appropriately justified in the project documentation, it is allowed to use computational and analytical methods. Wherein, availability of fire resistance test report for the load-bearing and enclosing structure according to GOST 30247.1 is required. The calculated risk is estimated on their basis». So, it remained to expect bodies of expertise to accept calculations on the basis of any calculation methods, if only they were based on fire tests results of similar constructions with the same fire-retardant coating. But, as you understand, the examination bodies do not require anything at all. 


\section{Civil Engineering Research Journal}

Building supervision bodies say: «once the project was examined in this appearance, we will accept it like this. What about fire resistance? We have no idea, this is not our field of activity».

One of the main reasons why we decided to write this articlewe think that recent fire tests of reinforced concrete structures conducted in 2017-2017 at All-Russian Scientific Research Institute of Fire Defense (VNIIPO) showed the susceptibility of such structures to explosive spalling. While engineering we expect the layer to protect the reinforcing cage from heat for 60 minutes/150 minutes, but in fact the armature is bare after 25-30 minutes of test! (Figure 2)

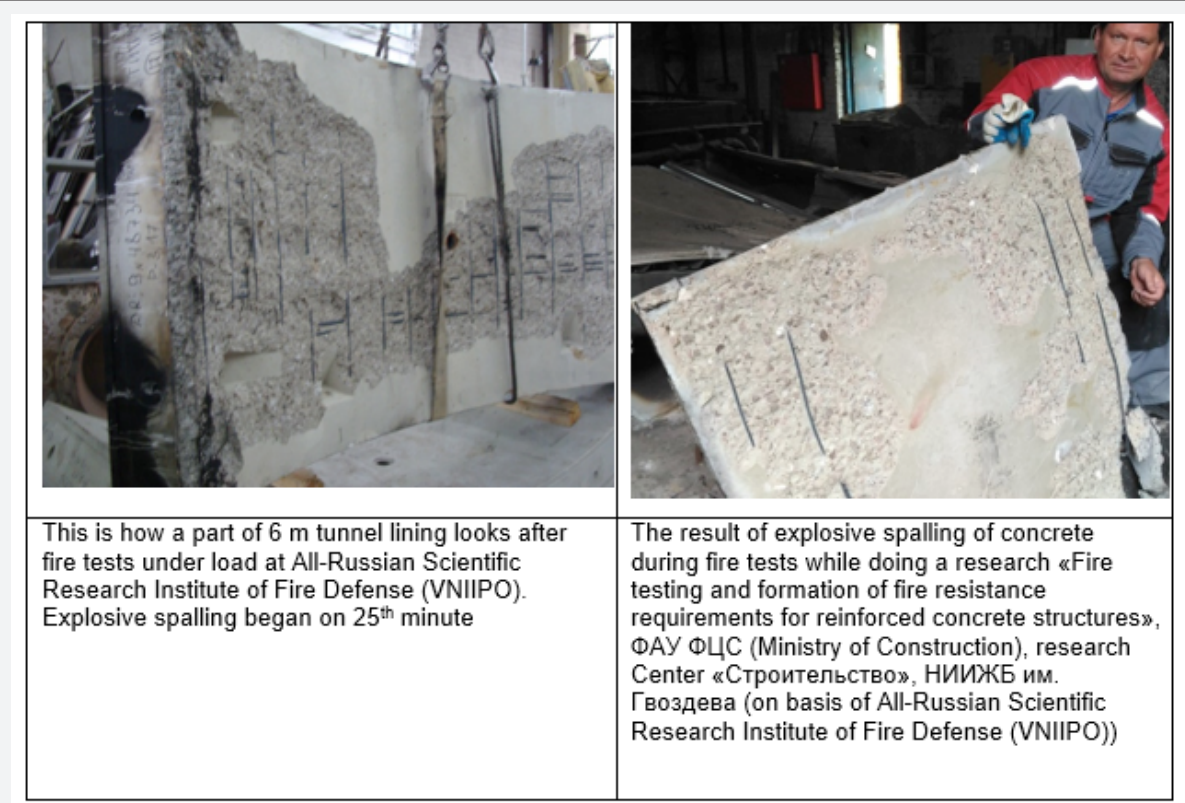

Figure 2: The result of explosive spalling of concrete during fire tests.

You can say that increase of fire resistance of reinforced concrete structures is now withdrawn from the legal field with its requirements for fire testing. All design and expert organizations take heat engineering calculations as evidence of fire resistance. Existing references to old tests conducted, for example, at AllRussian Scientific Research Institute of Fire Defense (VNIIPO) or Central Research Institute of Building Constructions (TSNIISK) 30 or even more years ago and the methods developed on the basis of this tests (fundamental with no doubt) are not quite correct, because no one has seen those protocols for a long time. You cannot apply them to modern calculations. There is a new armature, new supplements, etc. nowadays. Concerning calculations made without references to fire test reports - they are just theoretical works about expected limit of fire resistance.

\section{Why does explosive spalling of concrete happen?}

This process is regarded in many theoretical and experimental works, i.e

A. Khoury G.A. "Explosive spalling of concrete in fire” [3].

B. Shuttleworth P. "Fire protection of precast concrete tunnel linings on the Channel Tunnel rail Link" [4].

C. Ichikawa Y. "Prediction of pore pressure. Heat and moisture transfer leading to spalling of concrete during fire" [5].

D. Jansson R. and Bostrom L. "Fire spalling in concrete-the moisture effect" and another (Figure 3)

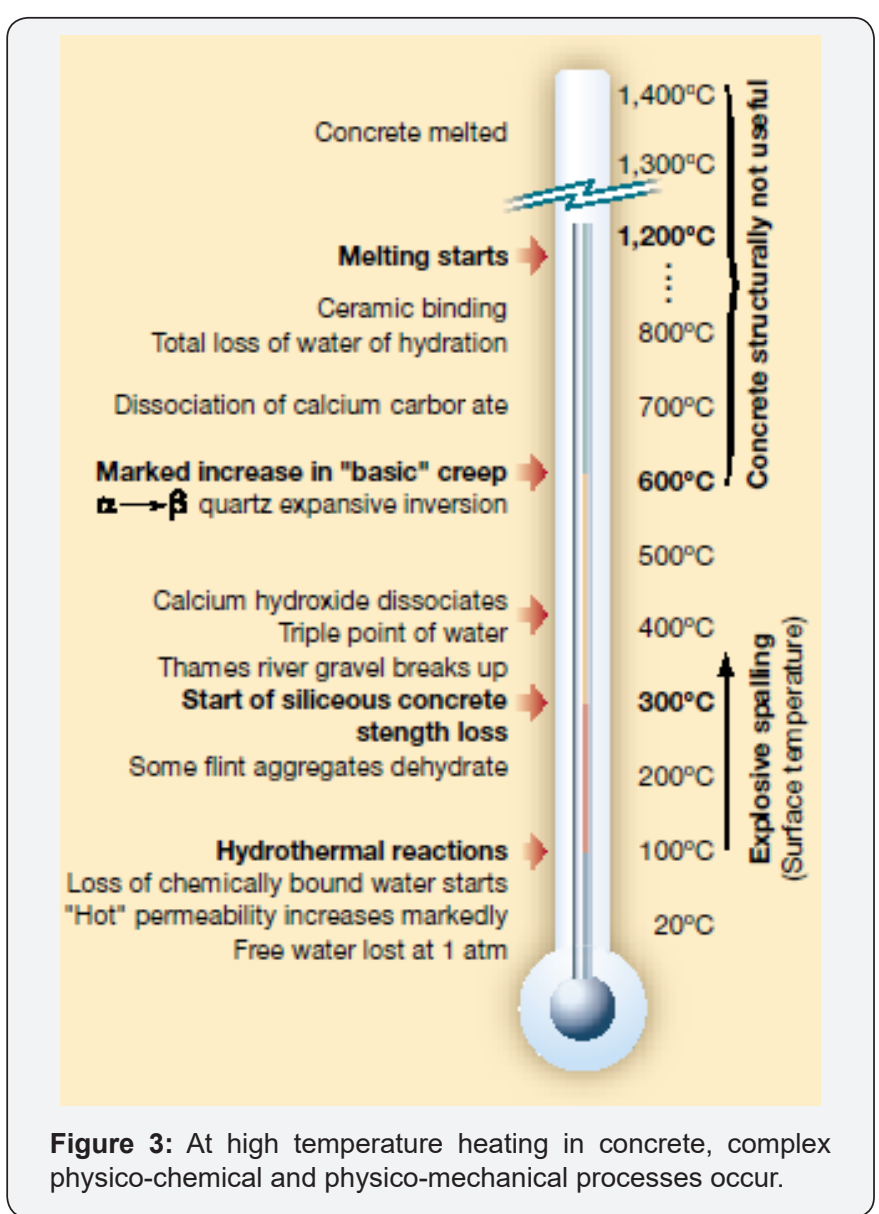




\section{Civil Engineering Research Journal}

At high temperature heating in concrete, complex physicochemical and physico-mechanical processes occur. Durability of material depends on properties of binders and dispersed filler composition. Decomposition of hydrates during heating of concrete leads to a breakdown of mechanical strength of hardened cement paste. Migration of chemically bound water, which mechanism is not studied enough, also affects cracking of concrete. Explosive spalling happens also due to tensile stresses arising because of steam pressure in pores and in addition to this, because of weakening of concrete after loosing the migrated water. The weakening can contribute to the destruction of material not only due to pressure but even under the action of thermal stresses, load-bearing stresses and difference in the coefficients of thermal expansion of various concrete fillers [6].

The relevance of the research is attributed to increasing pace of construction of deep-level tunnels. Fires in such facilities could be catastrophic, often resulting in massive loss of life and great material losses, and their suppression requires involvement of considerable forces and assets. During the construction and operation of road and subway tunnels, the protecting structuresreinforced concrete lining blocks have a higher moisture content, which in the event of fire in the early stages can lead to brittle failure of concrete tubing and the premature loss of their loadbearing capacity. So, they build subways, tunnels, bridges, underground parking's, etc., create special technical conditions with highest fire resistance requirements (such as R120-R240) for them, but honestly nobody knows the real characteristics of this construction [7].

To reduce the effects of brittle fracture of concrete in the protective layer of concrete structures anti-spall mesh is installed, or fire-retardant coating is used which reduces the intensity of heating of concrete during fire. However, recent studies have shown that the most effective way of protecting against brittle fracture of concrete from the point of view of labor and material cost is the use of additives in the concrete mixture in the form of polypropylene fibers. Earlier, experiments were carried out in VNIIPO with the polypropylene fiber "PROZASK IGS" to determine the actual limits of fire resistance of tunnel tubing and the influence of polypropylene fibers additives in concrete mix on the likelihood of brittle fracture of concrete. However, it seems impossible to assess the fire resistance of similar structures using numerical methods due to the lack of baseline data on the strength and thermo-physical properties of concrete with polypropylene fibers. To achieve this goal, studies were conducted of concrete strength under axial compression with the addition of polypropylene fibers in the amount of $1 \mathrm{~kg} / \mathrm{m}^{3}$ and experimental data of thermal characteristics of fiber-reinforced concrete at high temperatures were obtained. The paper presents the results of experiments on the samples of fiber concrete under axial compression when exposed to temperature in the range $20-800{ }^{\circ} \mathrm{C}$ (Figure 4).

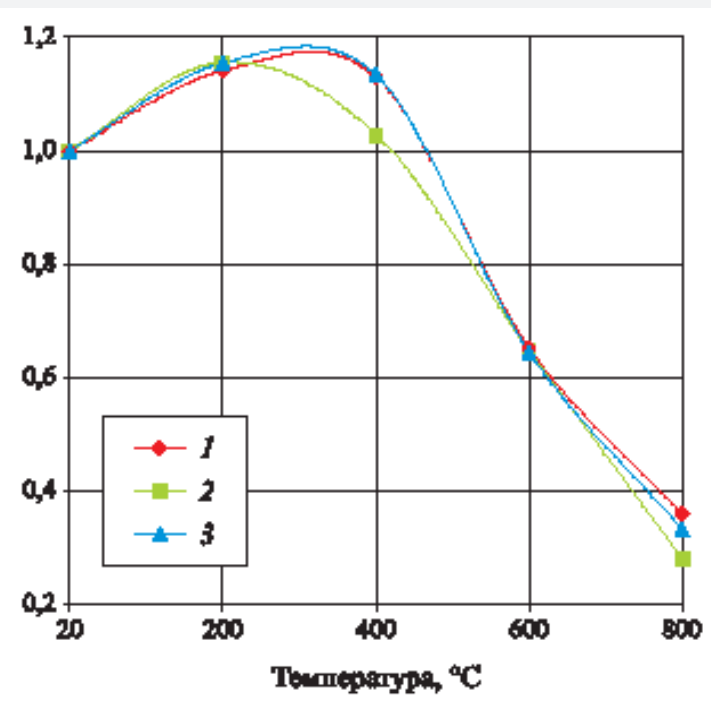

Figure 4: The process of the strength change of concrete with (blue and green) and without (red) additives during heating.

Graphics show the process of the strength change of concrete with (blue and green) and without (red) additives during heating. Analytical dependencies for determination of strength of concrete under compression were obtained with two types of polypropylene fibers at high temperatures. A comparison of the strength properties of the investigated concrete mixtures was carried out. It was established experimentally that when using the polypropylene fibers, the strength characteristics of fiber-concrete are reduced on average by $16 \%$, compared to the concrete without fiber additives, both at normal and high temperatures. As a result of processing of the experimental data by regression analysis the analytical dependencies were obtained for determination of strength characteristics of concrete under axial compression with the addition of domestic and imported fibers when exposed to high temperatures [7].

Experiments to determine the thermal properties of concrete with the addition of polypropylene fibers, were conducted during one-sided heating of board samples on the temperature regime of "standard fire". 


\section{Civil Engineering Research Journal}

In the presence of experimental data, by solving the inverse heat conduction problem using the previously developed computer program, the thermophysical characteristics (thermal conductivity and heat capacity) of fiber-reinforced concrete at elevated temperatures were defined. With increasing temperature, the thermal conductivity decrease is more intensive in concrete with added polypropylene fibers than that of concrete without additives. At the same time, the addition of fiber does not affect the intensity of increase of the heat capacity of concrete. The obtained dependences of thermophysical properties of concrete with domestic and imported polypropylene fibers on temperature increase make it possible to carry out calculations of heating of concrete structures with selected additives on a temperature regime of "standard fire". The conducted studies on the effect of temperature on the strength and thermal properties of concrete with addition of polypropylene fiber reinforcement can be used in calculation of the fire resistance of load-bearing and enclosing structures made of this type of fiber-reinforced concrete [8-12].

\section{References}

1. National Standards of Russia 30247.0 (1996) Elements of building constructions. Fire-resistance test methods. General requirements. System requirements.

2. National Standards of Russia 30247.1 (1996) Elements of building constructions. Fire-resistance test methods. Loadbearing and separating constructions. System requirements.

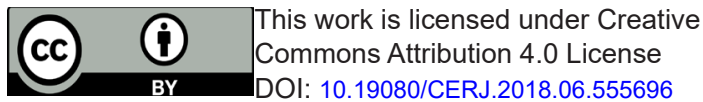

3. Korsun V, Vatin N, Korsun A, Nemova D (2014) Physical-Mechanical Properties of the Modified Fine-Grained Concrete Subjected to Thermal Effects up to $200{ }^{\circ} \mathrm{C}$. Applied Mechanics, and Materials 633634: 1013-1017.

4. Gravit TM, Dmitrieva Y (2012) Means of fire protection of building structures, Analysis of the general provisions of the Russian, and European regulations. Architecture, and Construction of Russia. 8 (2012): 24-29.

5. Telford T (2011) Fire Protection Engineering for New and Existing Tunnels.

6. Flassenberg G (2015) Reliable fire safety in accordance with new EU standards, Mauerwerk: 407-410.

7. Haack A (2002) Current safety issues in traffic tunnels. Tunnelling, and Underground Space Technology 17(2): 117-127.

8. Khoury GA (2011-2016) Explosive spalling of concrete in fire.

9. Shuttleworth P (2017) Fire protection of precast concrete tunnel linings.

10. Ichikawa Y (2000) Prediction of pore pressure. Heat and moisture transfer leading to spalling of concrete during fire.

11. Golovanov VI, Novikov NS, Pavlov VV, Kuznetsova EV (2017) Strength and thermos-physical properties of concrete with polypropylene fiber under standard temperature regimes Fire and Explosion Safety 26(5): 2017.

12. Golovanov V, Novikov N, Pavlov V, Antonov S (2000) Strength characteristics of fiber reinforced concrete for tunnel structures in high.

Your next submission with Juniper Publishers
will reach you the below assets
- Quality Editorial service
- Swift Peer Review
- Reprints availability
- E-prints Service
- Manuscript Podcast for convenient understanding
- Global attainment for your research
- Manuscript accessibility in different formats
( Pdf, E-pub, Full Text, Audio)
- Unceasing customer service
Track the below URL for one-step submission
https://juniperpublishers.com/online-submission.php

